\title{
HIV/Syphilis Coinfection in Patients with Uveitis
}

\author{
Juliet María Enriquez Puertas ${ }^{1}$; Isabel Ambou Frutos ${ }^{2}$; Neisy Valdésde Calzadilla ${ }^{3}$; Kenia \\ Romero Martínez ${ }^{4}$; Beatriz Muñoz Lorenzo ${ }^{5}$; Enrique Noa Romero ${ }^{6}$ \\ ${ }^{I}$ Graduate in Health Technology, Master in Infectious Diseases, Associate Researcher. AIDS Research \\ Laboratory, Mayabeque, Cuba. \\ ${ }^{2}$ Doctor in Medicine. Second degree specialist in Ophthalmology and first degree in Comprehensive \\ General Medicine, Master in Infectious Diseases, Assistant Professor. Cuban Institute of Ophthalmology \\ "Ramón Pando Ferrer", Havana, Cuba. \\ ${ }^{3}$ Doctor in Medicine. First degree specialist in Microbiology, Associate Investigator. AIDS Research \\ Laboratory, Mayabeque, Cuba \\ ${ }^{4}$ Degree in Biochemistry, Master inScience, Assistant Researcher. AIDS Research Laboratory, \\ Mayabeque, Cuba. \\ ${ }^{5}$ Doctor in Medicine. First degree specialist in Microbiology. Cuban Institute of Ophthalmology "Ramón \\ Pando Ferrer", Havana, Cuba. \\ ${ }^{6}$ Degree in Biology, Master in Microbiology, Doctor of Science, Assistant Professor, Senior Researcher. \\ AIDS Research Laboratory, Mayabeque, Cuba.
}

*Corresponding Author: Juliet María Enriquez Puertas, AIDS Research Laboratory. Autopista Nacional y Carretera de Jamaica. San José de las Lajas. Mayabeque. Cuba.

\begin{abstract}
Ocular syphilis has reemerged as an important cause of uveitis, associated epidemiologically with human immunodeficiency virus infection. To determine the HIV / syphilis coinfection in Cuban patients with uveitis in the period of one year. The study was conducted in patients with intraocular inflammation examined in the uveitis service of Cuban Institute of Ophthalmology "Ramón Pando Ferrer", aone-yearperiod. For detection of antibodies against HIV, a diagnostic algorithm was applied, including screening tests by means of the third and fourth generation enzyme linked immunosorbent assay, and western blot confirmatory tests for HIV-1 and HIV-2. For serological diagnosis of syphilis, the samples confirmed as positive for HIV were subjected to non-treponemal and treponemal tests. A total of 95 serum samples of patients with uveitis were evaluated, three of which were positive for both syphilis and HIV-I. In all three cases, uveitispresented bilateral form. Uveitis in two patients presented as posterior uveitis and the other one as panuveitis.CD4 + values ranged from 250 to 409 cells $/ \mathrm{mL}$. These findings hold that uveitis can often lead to the diagnosis of HIV infection and syphilis. They also corroborate that intraocular inflammation in patients co-infected with HIV / syphilis can occur severely, so it is necessary to diagnose infections early and apply appropriate treatment to prevent irreversible complications.
\end{abstract}

Keywords: HIV/syphilis coinfection, human immunodeficiency virus, syphilis, uveitis, ocular syphilis

\section{INTRODUCTION}

Uveitis is inflammation of the internal ocular structures and the most common form of inflammatory eye disease. It has a considerable impact on visual health, being responsible for $2.8-10 \%$ of blindness in much of the world. Its etiology can include alterations of the immune system or infectious diseases. ${ }^{[1]}$

Treponema pallidum is the etiologic agent of syphilis, one of the infections related to inflammation of the uveal tract. Syphilitic uveitis has recently regained attention due to the reemergence of syphilis worldwide. In the clinical course of this infection, four stages are described: primary, secondary, latent and tertiary syphilis. Ocular syphilis is very rare, it is equivalent to $1-2 \%$ of uveitis and can occur at any stage except the primary one, but it is more frequent during the secondary or latency stages. However, syphilitic uveitis can manifest itself clinically in various ways, often leading to delay in diagnosis and treatment, resulting in a serious ocular complication and irreversible loss of vision. $^{[2]}$

Syphilis is currently epidemiologically associated with human immunodeficiency virus (HIV) infection. Both are considered sexually transmitted infections (STIs) with significant 
morbidity and mortality in the younger sectors of the population. According to the World Health Organization (WHO), 36.9 million people lived with HIV in 2017 and estimates that annually there are about 357 million new cases of STIs in the world, of that total, 5.6 million are due to syphilis. ${ }^{[3,4]}$

HIV infection can modify the response to treatment of $T$. pallidum infection and clinical development, favoring atypical clinical pictures. In coinfected individuals, an increase in ophthalmic and neurological conditions may be common early. ${ }^{[5]}$

Due to the fact of not finding enough reports of studies in Cuba on HIV / syphilis coinfection in patients with intraocular inflammation, and the importance of early diagnosis of these cases, it was proposed to determine coinfection by these sexually transmitted pathogens in Cuban patients with uveitis within a year.

\section{Materials AND MethodS}

A descriptive and cross-sectional study was carried out in patients with intraocular inflammation examined in the uveitis service of the "Ramón Pando Ferrer" Cuban Institute of Ophthalmology, in a period of one year.

For the detection of antibodies against HIV, the diagnostic algorithm established in Cuba was applied, which includes screening tests by means of the third and fourth generation enzyme-linked immunosorbent assay (ELISA), and confirmatory by western blot for HIV-1 and HIV-2. ${ }^{[6]}$

Non-treponemal and treponemal tests were performed on the samples confirmed as positive for HIV, which detect nonspecific and specific antibodies, respectively, taking into account the methodology used in Cuba to establish the diagnosis of syphilis. ${ }^{[6]}$

An epidemiological survey was applied to the patients included in the study and demographic, clinical and epidemiological data were obtained. The variables analyzed were: age, sex, sexual orientation, location and laterality of intraocular inflammation, and CD4 cell levels.

\section{RESULTS AND DISCUSSION}

A total of 95 serum samples from patients with uveitis were evaluated, seven $(6.6 \%)$ were confirmed positive for HIV-1 and three (3.2\%) of them showed reactivity also for syphilis. No patient was HIV-2 seropositive.

The average age of patients with uveitis and coinfected with HIV / syphilis was 55 years in a range between 49 and 65 years of age. The three patients are male, two (66.7\%) of them are men who have sex with other men (MSM).

When analyzing the characteristics of the ocular lesions, it was evidenced that in one of the patients the inflammation presented as posterior uveitis (33.3\%) and in the rest as panuveitis for $66.7 \%$. Regarding the laterality of the uveitis, it was bilateral in the three patients. CD4 + values ranged from 250 to 409 cells $/ \mathrm{mL}$ (average 320 cells/mL).

The study determined that $3.2 \%$ of patients with uveitis were co-infected with HIV / syphilis. Currently both STIs, due to their high incidence, constitute a serious public health problem. Recently, the Center for Disease Control (CDC) reported a significant increase in cases of primary and secondary syphilis co-infected with $\mathrm{HIV}^{[7]}$. Likewise, in studies evaluating HIV/STI coinfection carried out in Cuba between 2015 and 2016, they showed that syphilis was the most frequent STI associated with HIV infection $^{[8,9]}$. In addition, in a study of the behavior of ophthalmological diseases in patients with HIV-AIDS at the Cuban Institute of Ophthalmology"Ramón Pando Ferrer", stated that ocular syphilis was the most frequent ophthalmological disease ${ }^{[\mathbf{1 0 ]}}$. In contrast, in the tertiary uveitis service at Tianjin Medical University Eye Hospital, between 2011 and 2016, of 27 patients with syphilitic uveitis, only one was HIV positive. ${ }^{[11]}$

Concomitant HIV infection and syphilis were diagnosed in the three co-infected patients in the study based on evaluation of uveitis. Similarly, in a series of cases in the United States and Europe, it was shown that $52 \%$ of patients received the diagnosis of HIV infection in conjunction with the diagnosis of syphilis ${ }^{[12]}$. These results and those described by other authors ${ }^{[13,14,15]}$ suggest that ocular syphilis may be the first manifestation of HIV infection and that frequently the ophthalmological evaluation can lead to the diagnosis of infection by this retrovirus.

There are several hypotheses regarding the increase in the dual infection of HIV and syphilis. Both infections have similar transmission mechanisms and risk factors, and there is also evidence that suggests a synergism between the two pathogens. Syphilis facilitates the transmission of HIV by breaking the protective mucosal barrier with the formation of the syphilitic chancre that functions as a gateway for HIV and recruits susceptible immune system cells to the site of infection, 
allowing easy access of the virus to the blood circulation of the host and promotes viral replication. For its part, HIV can modify the natural course of syphilis in these patients by modulating the immune response to $\mathrm{T}$. pallidum, favoring the development of more aggressive manifestations, rapid progression to the tertiary stage, shortening the latency period, for what is common in these patients is primosecondaryism that leads to ocular and central nervous system involvement. ${ }^{[16,17]}$

The mean age of the patients at work (55 years) differs from the mean age of the patients studied by Zhang ${ }^{[11]}$ and Widdrington ${ }^{[17]}$, which was 45.5 and 49.7 years of age, respectively.

The increase in high-risk sexual behavior results in an increase in the rate of STIs, including syphilis, among people living with HIV / AIDS. During the last decade, the proportion of syphilis infection has increased particularly in $\operatorname{MSM}^{[11,15,17,18]}$. The results of the research are consistent with the previous approach and with the results of a national study on venereal syphilis in MSM carried out at the Hospital Center of the Institute of Tropical Medicine "Pedro Kouri", in which, of 81 individuals with syphilis, 75 were HIV positive. Considering that this center is the reference clinic for the care of this type of patients in Cuba, it justifies that the percentage of HIV-positive people is higher in relation to those who do not present this condition. ${ }^{[20]}$

Although syphilis can affect the eye in different ways, uveitis is the most common ocular presentation. The diagnosis of ocular syphilis is based on ophthalmological findings; however, it is often challenging due to the lack of pathognomonic symptoms ${ }^{[14]}$. Despite the above, in the study there was no diversity in the ocular findings of syphilis since in the three coinfected patients the posterior segment of the uvea was affected, in the form of panuveitis in $66.7 \%$ and the rest of uveitis later, a result that coincides with that of other authors ${ }^{[14,17,19]}$.Similarly, Mathew ${ }^{[21]}$ and Hughes ${ }^{[22]}$ reported a higher proportion of panuveitis and posterior uveitis in HIV-infected patients than in seronegative patients.

Such findings suggest that HIV infection can modulate the severity of ocular syphilis. Posterior uveitis or panuveitis caused by syphilis can cause severe signs of vision loss or blindness and a high risk of penetration of $\mathrm{T}$. pallidum into the central nervous system $^{[14,15,18,19]}$.
Ophthalmological diseases commonly occur in patients with CD4 counts below 200 cells $^{[23]}$. Along the same lines, there are authors who support the association between posterior uveitis and panuveitis with low CD4 cell counts ${ }^{[11]}$. In the study, uveitis in coinfected patients was not related to CD4+ cell values that ranged between 250 and 409 (average 320 cells $/ \mathrm{mL}$ ), which is consistent with the work of RoseNussbaumer ${ }^{[24]}$ whose values ranged between 207-1777 cells/mL (median 421 cells $/ \mathrm{mL}$ ) and with $\mathrm{Ambou}^{[10]}$, where $44.4 \%$ of patients with manifestations of ocular syphilis had values greater than 200 cells $/ \mathrm{mL}$.

\section{CONCLUSions}

The findings obtained in our work support that uveitis can frequently lead to the diagnosis of HIV infection and syphilis. They also corroborate that intraocular inflammation in patients coinfected with HIV / syphilis can present in a serious way, which is why it is necessary to diagnose infections early and apply the appropriate treatment to prevent irreversible complications such as loss of vision and the involvement of the central nervous system.

\section{REFERENCES}

[1] Miserocchi E, Fogliato G, Modorati G, Bandello F. Review on the worldwide epidemiology of uveitis. Eur J Ophthalmol. 2013; 23 (5):705-17

[2] Pratas AC, Goldschmidt P, Lebeaux D, Aguilar $\mathrm{C}$, Ermark N, Benesty $\mathrm{J}$, et al. Increase in ocular syphilis cases at Ophthalmologic Reference Center, France, 2012-2015. Emerg Infect Dis. 2018 Feb; 24 (2): 193-200. doi: 10.3201/eid2402.171167

[3] UNAIDS|2018 reference. http//www.unaids. org/es/resources/documents/2018/UNAIDS_fac t-sheet

[4] World Health Organization.Global Health Sector Strategy on Sexually Transmitted Infections, 2016-2021.https://www.who.int/re $\mathrm{p}$ roductivehealth/publications/rtis/ghss-stis /en/

[5] Callegari FM, Pinto-Neto LF, Medeiros CJ, Scopel CB, Page K, Miranda AE. Syphilis and HIV co-infection in patients who attend an aids outpatient clinic in Vitoria, Brazil. AIDS Behav. 2014 Jan; 18 (01): 10.1007/s10461-013-0533-X

[6] Ministry of Public Health. National strategic plan for the prevention and control of STIs, HIV and hepatitis 2019-2023. Cuba: MINSAP; 2019

[7] Centers for Disease Control and Prevention (CDC) Sexually transmitted disease surveillance 2013. Atlanta: U.S. Department of Health and Human Services; 2015 [Fecha de 
acceso 1 de enero de 2015] http://www.cdc.gov /std/syphilis2013/syphilis-2014-all-profiles.pdf.

[8] Duque R. Evaluation of the diagnostic and clinical performance of a rapid test to screen for venereal syphilis (IPK, January-December, 2015) [Job to opt for the title of First-Degree Specialist in Microbiology].La Habana: IPK; 2016.

[9] Noda A, Matos N, Orestes B, Rodríguez I, Stamm LV. First Report of the 23S rRNA Gene A2058G Point Mutation Associated With Macrolide Resistance in Treponema pallidum From Syphilis Patients in Cuba. Sex TransmDis. 2016; 43 (5): 332-34.

[10] Ambou I. Rodríguez N, Ramos L, Vilches DC, Osorio L, Padilla CM. Ophthalmological Manifestations in Patients with Syphilitic Uveitis Treated in the ICO "Ramón Pando Ferrer".EC Ophthalmology.2018;9(8): 609-616.

[11] Zhang X, Du Q, Ma F, Lu Y, Wang M, Li X. Characteristics of syphilitic uveitis in northern China. BMC Ophthalmology 2017; 17:95| DOI 10.1186/s12886-017-0491-6

[12] Tucker JD, Li JZ, Robbins GK, Davis BT, Lobo AM, Kunkel J, Papaliodis GN, Durand ML, Felsenstein D. Ocular syphilis among HIV-infected patients: a systematic analysis of the literatura. Sex Transm Infect. 2011; 87(1): 4-8| DOI:10.1136/sti.2010.043042.

[13] Kunkel J, Schürmann D, Pleyer U, Rüther K, kneifel C, Krause L, Reichert M, Ignatius R, Schneider T. Ocular syphilis-indicator of previously unknown HIV-infection. J infect. 2009; $58 \quad$ (1): $\quad 32-6 \quad$ https:// doi.org/10.1016/j.jinf.2008.11.004.

[14] Lee SY, Cheng V, Rodger D, Rao N. Clinical and laboratory characteristics of ocular syphilis: a new face in the era of HIV co-infection. J Ophthalmic Inflamm Infect 2015; 5: 56 DOI 10.1186/s12348-015-0056-X

[15] Li JZ, Tucker JD, Lobo AM, Marra CM, Davis BT, Papaliodis GN, Felsenstein D, Durand ML, Yawetz S, Robbins GK. Ocular Syphilisamong HIV-InfectedIndividuals. CID 2010;51(4):46847 | DOI: 10.1086/654797

[16] Mejía AM. Complications of coinfection in hepatitis B - C and syphilis in patients with human immunodeficiency virus. Job to opt for the title of medical. Guayaquil University.
Ecuador. Faculty of Medical Sciences; 2017 2018

[17] Widdrington JD, Ashfaq I, Puvaneswaran B, Ong EL, Schwab U, Price DA, Schmid ML, Pandit R. Clinical missed opportunities to diagnose syphilis prior to the development of sight-losing uveitis. J r Coll Physicians. 2017; 47: 129-34 | DOI: 10.4997/JrCPe.2017.204 PAPER

[18] PugaMAM,Bandeira LM, Pompilio MA, Rezende GRd,SoaresLS, de CastroVdOL, et al. Screening for HBV,HCV,HIV and syphilis infections among bacteriologically confirmed tuberculosis prisoners: An urgent action required. PLoSONE 2019; 14(8):e0221265. https://doi.org/10.1371/journal.pone.0221265

[19] Ambou Frutos I, Rodríguez Ahuar N, Ramos Bello L, Vilches Lescailles D, Osorio Illas L, Padilla González CM. Behavior of eye diseases in HIV-Aids patients. Rev Cubana Of talmol 2017; 30(2): 1-15. http://scielo.sld.cu/ scielo.php?script=sci_arttext\&pid=S086421762017000200006\&lng=es.

[20] Morales M. Venereal syphilis in Cuban men who have sex with men. IPK, October 2015June2016. La Habana. Job to opt for the title First Degree Medical Specialist in Microbiology]. Institute of Tropical Medicine "PEDRO KOURÍ; 2017.

[21] Mathew RG. British Ocular Syphilis Study (BOSS): 2-year national surveillance study of intraocular inflammation secondary to ocular syphilis. Invest Ophthalmol. 2014; 55:5395-5400

[22] Hughes EH. Syphilitic retinitis and uveitis in HIV-positive adults. Clin Experiment Ophthalmol. 2010; 38:851-856

[23] Suranagi DM, Sagar SN, Sungar M.A study of ocular manifestations in patients with HIVAIDS infection and correlation with CD4 count. J.Evid, Based Med. Healthy. 2017; 4 (32), 1921-1924. DOI: 10.18410/ jebmh/ 2017 1375

[24] Rose-Nussbaumer J, Goldstein DA, Thorne JE, Arantes TE, Acharya NR, Shakoor A, et al. Uveitis in human immunodeficiency virusinfected persons with CD4+ T-lymphocyte count over 200 cells $/ \mathrm{mL}$. Clin Experiment Ophthalmol. 2014; 42: 118-125 | DOI: $10.1111 /$ ceo. 12141

Citation: Juliet María Enriquez Puertas et.al, "HIV/Syphilis Coinfection in Patients with Uveitis", International Journal of Research Studies in Medical and Health Sciences. 2020; 5(9): 10-13.

Copyright: (C) 2020 Juliet María Enriquez Puertas et.al, This is an open-access article distributed under the terms of the Creative Commons Attribution License, which permits unrestricted use, distribution, and reproduction in any medium, provided the original author and source are credited. 